\title{
ALUMINIUM IN ELECTRICAL ENGINEERING
}

A HIGHLY successful symposium on "Aluminium in Electrical Engineering", organized by the Aluminium Development Association, was held in London at the Institution of Electrical Fngineers during Mry 16-17. It was attended by some five hundred representatives of the electrical engineering and aluminium industries and of electrical generating and distribution authorities, one-tenth of whom came from overseas. After an inaugural luncheon, at which the principal guest was the Right Hon. Reginald Maudling, M.P. (H.M. Paymaster-General and a former Minister of Supply), successive sessions of the symposium were devoted first to general and economic questions related to aluminium usage in electrical engineering, and then to its use in transmission and distribution lines, and in electrical equipment. The papers considered at each of the three sessions were introduced by a rapporteur, and this was followed at each session by an unflagging and constructive discussion. 'The full proceedings, including reports of the discussion and the authors' replies, will be published later in the year.

The purpose of the symposium was to take stock of the present-day position in a field of application which dates back almost to the beginnings of the aluminium industry and to-day absorbs about 15 per cent of the world's fast-growing supplies of the metal, which last year reached $3 \frac{1}{4}$ million tons of new metal alone. C. H. E. Ridpath and D. F. J. Worth first gave a general account of the main properties and electrical uses of the metal. Its key property as a conductor metal is, of course, its high electrical conductivity (61 per cent that of copper): in addition, it weighs only half as much as its electrical equivalent of copper and is inherently stable in the atmosphere; and research and development work have led to standards of composition and performance in which these properties are coupled to suitable mechanical strength for a wide range of electrical engineering uses, including bare overhead cable, insulated cable and windings for equipment. 'The main technical problem, which has been recognized for nearly a century, is that of obtaining joints of high strength and low resistance between aluminium on one hand, and aluminium or copper on the other. The fundamentals of this problem were presented by J. C. Bailey and P. Gregory. 'The tough, continuous oxide film, which forms spontaneously on aluminium exposed to the air, has to be broken up or removed before a satisfactory joint can be obtained; but there exist a wide variety of ways in which this can be carriod out, including soldering, brazing, bolting (under moderate pressure), 'crimping' (under greater pressure), arc-welding, resistance-welding and coldpressure welding. Naturally, all these came under discussion in the detailed sessions, but Bailey and Gregory emphasized that the techniques used should be designed to meet aluminium's own properties, and not merely adapted from those worked out for other metals.

The economics of aluminium usage were generally surveyed at the opening session by Dr. E. G. West, technical director of the Association, but this aspect also received a good deal of detailed attention at later sessions. From a study of the supply position of aluminium in relation to the metals copper, zinc and lead, with which it competes in this field, Dr. West concluded that the increasing use of aluminium is to be expected because of its favourable longterm supply position, its strong competitive position relative to these other metals, and the relative stability of its price. It was evident, however, that while these conclusions were broadly accepted by the conference, there was some hesitancy regarding future price trends because of recent attempts to

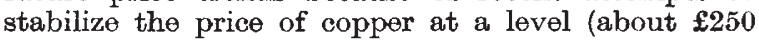
per ton) much lower than that which it commanded only a year ago. Could such price control be maintained in face of the wide spread in the yields of copper from its various ores, and the consequent wide range in costs of production ? In the nature of things, this question could not be answered, but it was noted that the present price-relation between copper and aluminium was about the same as in 1939; and by that date aluminium had already played an important part in the world's overhead supply lines, and insulated aluminium cables and aluminium-wound transformers were by no means unknown. Such hesitancy as was shown in the discussions was thus confined to these latter applications, which had been greatly stimulated in recent years by a more favourable aluminium/copper price relation than subsists to-day, and on which a number of papers of great technical interest were presented. It seemod evident that such developments would be actively pursued and evaluated by trial under service conditions, even if their large-scale realization might in some cases have suffered a temporary setback.

Papers on transmission lines for high voltages $(66 \mathrm{kV}$. and more) and on distribution lines (up to $33 \mathrm{kV}$.) were presented by G. B. Jackson (Central Electricity Authority) and by R. Cloke and R. Fyfe (Eastern Electricity Board), respectively. Jackson noted that the Central Electricity Authority controls more than 7,000 circuit miles of lines at voltages up to $275 \mathrm{kV}$., the great majority of which are of steel-cored aluminium. Three standard sizes of composite conductor are normally used, but extra large conductors have been prepared for long spans crossing rivers: for example, the main span of the Severn crossing $(5,310 \mathrm{ft}$.) will employ steel-cored aluminium conductors nearly $1.7 \mathrm{in}$. in diameter, under a tension of nearly 27 tons, and a still larger conductor is being planned. Greasing of the steel core with a metal soap is now usual to avoid corrosion in industrial atmospheres; and it was mentioned that conductors erected by modern standards should have a life of forty years or more. The wide. spread use of such cables in many countries is, of course, well known, but some interesting differences in practice came to light during the discussions. These related both to jointing methods and to conductor composition. A point of interest was made by J. Staley (Reynolds Metals Co., of the United States), who referred to the probability that aluminized steel wire would replace galvanized steel in such conductors.

Discussion of the use of aluminium conductors in insulated power cables, based on a paper by G. F. Pierson (Midlands Electricity Board), centred largely on jointing problems and on questions of economics. There was surprisingly little reference from British 
speakers to aluminium-sheathed power cables, in view of their growing use in Britain; but R. C. Mildner referred to aluminium sheathing in telecommunications cables, and it was evident from comments by a number of speakers from overseas that aluminium sheathing (in place of lead) would be used in future for a wide range of cables as manufacturing techniques improve. Bus-bars and bus-bar jointing were discussed by A. R. Parish : many satisfactory installations go back thirty years or more, and jointing need not be a serious problem. The most desirable development here is the production of highstrength aluminium (magnesium-silicon) alloys showing a minimum loss of conductivity due to alloying constituents, for use in a.c. circuits.

The closing session of the symposium was concerned with aluminium in electrical equipment, and provided much of the most interesting new material. Aluminium windings for transformers and the like were described by F. W. Gee and R. J. Gresley (Ferranti, Ltd.), who stressed the need, referred to above, for manufacturers to gain experience with such constructions now, against the time when the economic advantage of aluminium, which already exists in some cases, becomes more general. In this application, as in all others involving aluminium windings, the need to use an aluminium conductor having a cross-section some 60 per cent greater than that of the equivalent copper conductor involves an increase in size of the apparatus if conventional insulated conductors are employed. Cases occur where such an increase would not be acceptable; but even when this does not apply, increased size would involve the use of more iron in the magnetic circuit and hence greater iron losses. Gee and Gresley referred to the interesting possibility of avoiding such increase by using aluminium conductors protected by anodic oxide layers which require no further insulation. The same possibility was discussed in greater detail by J. Staley, who presented a paper, not previously available as a preprint, on anodized aluminium strip conductors. Other uses of aluminium which were discussed included structural applications, for example, transformer tanks, whore the low susceptibility of the metal could lead to economies due to elimination of losses arising from stray flux, and the use of die-cast aluminium in the equipment of telephone exchanges.

The symposiurn was accompanied by a compre. hensive exhibition illustrating the matters discussed and by demonstrations of arc-welding and coldpressure welding techniques. Its organization reflects the highest credit on all concerned, and the published proceedings, when available, will be a valuable contribution to the literature of the subject.

$$
\text { L. V. ChultoN }
$$

\section{CLEAN FOOD}

$\mathrm{T}$ HE 108th meeting of the Nutrition Society (49th meeting of the Scottish Group) held in the Physiology Department, University of Aberdeen, on April 20, took the form of a symposium on "Clean Food". 'This was divided into three main papers, and five shorter papers dealing with particular aspects. In his introduction, the chairman, Sir Stanley Davidson, indicated the importance of clean food in preventing food-poisoning and the important parts played by the sanitary inspector, medical officer of health and bacteriologist in looking after the health of the community from this point of view.

In his paper on public health aspects of foodpoisoning, Dr. Kenneth Cowan, chief medical officer of health, Department of Agriculture for Scotland, stated that the public health issues involved in food-poisoning are related to the immediate action required to investigate and control outbreaks of foodpoisoning, and to the education in hygiene of those engaged in the handling, storage and preparation of food.

An adequate alarm system in the form of prompt notification by medical practitioners and a thorough investigation by the medical officer of health leads to a knowledge of the types of bacteria and foodstuffs most likely to be associated with poisoning, thus making easier the task of establishing the cause of an outbreak.

When outbreaks occur in more than one family the prime duty of investigators is to trace the contaminated food back to a common source where, in their efforts to find the causal agent, attention will be given to the general hygienic conditions, and personal hygiene and history of recent illnesses among the staff. Early action is the most important factor in finding the causal agent.

'The principles of prevention are relatively simple, being a high standard of personal hygiene among those handling food and adequate precautions against contamination in storage. This involves education of food worker's in the principles of hygiene and the provision of premises which will enable the principles to be put into practice.

In describing the bacteriology of food poisoning Prof. J. W. Howie (Department of Bacteriology, University of Glasgow) pointed out that a recent report by the Public Health Laboratory Service showed that the majority of food-poisoning incidents successfully investigated in 1955 were caused, in order of importance, by salmonellas, staphylococei and Clostridium welchii. Of the other organisms known to cause food poisoning the most dangerous is Clostridium botulinum.

More than three hundred different types of salmonellas have now been identified. In Britain Salmonella typhi-murium is by far the commonest isolated from cases of food-poisoning. Rodents, certain farm animals and certain domestic animals may become salmonella-carriers and therefore a source of infection. for man. The part played by human carriers in spreading infection is slight compared with that attributable to animal carriers. The commonest vehicles of salmonellas are meat, milk, artificial creams and eggs. The prevention of this type of infection, which would reduce foodpoisoning to manageable proportions, involves control over distribution of particularly susceptible foodstuffs, higher cooking and lower storage temperatures for susceptible foods and more combined operations by public health officers and bacteriologists to discover more precisely which food ingredients carry the greatest risks.

In staphylococcal food poisoning the human carrier is most important. Staphylococci capable of producing the enterotoxin responsible for poisoning symptoms are to be found in the human nose and on the skin.

Clostridium welchii, which forms spores, is more resistant to heat than salmonellas or staphylococci. These spores resist temperatures of $100^{\circ} \mathrm{C}$. for an 